\title{
The Effect of a Topic-Based Paired Conversation Activity on the Confidence of Japanese EFL Students to Utilize English Orally
}

\author{
Christopher DeSteffen ${ }^{1}$ \\ ${ }^{1}$ Seirei Junior and Senior High School, Seto, Japan \\ Correspondence: Christopher DeSteffen, Seirei-cho 2, Seto City, Japan, 489-0863. E-mail: desteffen@gmail.com
}

Received: April 29, 2015 Accepted: May 14, 2015 Online Published: June 2, 2015

doi:10.5430/ijelt.v2n2p32 URL: http://dx.doi.org/10.5430/ijelt.v2n2p32

\begin{abstract}
The purpose of this study was to analyze the effect of the researcher-designed Topic Talk (TT) activity on the students' confidence to utilize English orally. The research question was: Can topic-based paired conversations utilizing a structured rotation technique improve the confidence in speaking English for EFL students? Mixed-methods research techniques were used in this project. A pre and post intervention survey was used to assess the students' confidence in their ability to utilize English orally. Qualitative data included teacher observations of student interactions. An item analysis revealed significant positive gains in responses to two survey questions and moderate gains in several others. Observational data revealed that the frequency of L1 use had decreased by the conclusion of the intervention and the average number of students unable to converse decreased significantly by the final week of the intervention. Implications applicable to educators working in similar environments are discussed.
\end{abstract}

Keywords: language anxiety, oral conversation, efl, speaking, Japan

\section{Introduction}

While working as an instructor of English oral communication in Japan for more than five years it has become apparent that the majority of Japanese learners have difficulty utilizing English orally. The apparent lack of confidence to utilize English verbally has become an increasingly vexing issue. Students in my tenth grade oral communication class have studied English regularly for at least three years, but many have difficulty maintaining a basic, unstructured, casual conversation. My struggles as an oral communication teacher have revealed that most students are focused in class, but reluctant to volunteer opinions, ask questions, or challenge what has been communicated during the lesson. While attempting to overcome student reticence, instruction in my classroom has included a variety of individual, pair, and group activities to provide opportunities for students to utilize the language in less-stressful situations. Students were often presented with think-pair-share activities prior to being directly queried. Despite sufficient preparation time, students remained hesitant to respond to inquiries. In other cases, students were compelled to consult a classmate and confirm their response before speaking in front of their peers. Many of these issues hindered the ability for students to foster competent communicative ability through English.

Several factors may prevent Japanese EFL learners from becoming proficient oral communicators. Sakui (2007) claimed that the primary purpose of studying English in Japan was to prepare students for junior and senior high school, and university entrance examinations, in addition to improving communicative discourse. She asserted that Japanese educators often struggled to implement and balance both goals successfully. One factor that may have influenced this unbalance was that English speaking sections were omitted from the entrance exams, so oral communication practice was often sacrificed for vocabulary, grammar, and listening exercises. Japanese teachers had little incentive to have their students utilize limited classroom time conversing and completing tasks that were unrelated to entrance examinations. Osterman (2014) recommended that a communicative classroom, in lieu of the traditional grammar-intensive pedagogy, would be more conducive to the facilitation of English language learning.

Other prominent factors resulting in lack of English oral proficiency were Japanese cultural norms and expectations. Saito and Ebsworth (2004) described Japan as a society that valued indirect speech and acceptance of group values. They contended that Japanese were opposed to the use of questioning as a tool to elicit original opinions and ideas and preferred reticent rather than active participation. Additionally, they claimed that the society is perfectionist in 
the sense that they do not respond to an inquiry unless they are entirely confident in their response. While societal norms have naturally evolved as a result of globalization, these intrinsic values still remain prominent in aspects of everyday life.

In an attempt to cultivate a more communicative classroom, I began to investigate methods of improving EFL student discourse, specifically in the Japanese classroom. Researchers have recommended several strategies to increase student dialogue. Harumi (2011) contended that communication activities should be designed to develop learner confidence and facilitate learner autonomy in a classroom environment that encourages mutual participation. Watanabe (2013) similarly argued that learners need opportunities for student-centered and individually focused activities on realistic issues. Through an action research project, Talandis Jr. and Stout (2014) determined that frequent assessments could help motivate reluctant learners to practice with greater focus and intensity and be used as a means for identifying areas of improvement. With these recommendations in mind, I designed an action research project to study the effect of a researcher-developed Topic Talk (TT) intervention activity on the confidence of students to utilize English orally.

\section{Methodology}

\subsection{Overview of the Study}

The purpose of the action research study was to analyze the effect of the Topic Talk (TT) activity on the students' confidence to utilize English orally. The researcher-designed intervention was the independent variable and involved face-to-face conversations between peers about a pre-determined topic. Students were assigned a random partner and instructed to converse for a period of one to three minutes regarding the assigned topic for the week. During each lesson, students formed three unique pairs and with each successive conversation, students were expected speak for a slightly longer period of time. The first conversation was limited to one minute, the second pairing was two minutes, and in the final rotation students were instructed to speak for three minutes.

The objective of the research was to determine if student confidence in the use of oral English increased as a result of the intervention. In addition to the pair-rotation strategy, participants were provided with a Question-Answer-Comment (QAC) organizer designed to assist students in brainstorming various questions and comments in preparation for weekly intervention. The organizer consisted of three columns. The first column contained stems of questions which students had previously studied. The second column contained the stem of an appropriate response to the related question. The final column of the organizer was for students to insert a potential comment or conversation rejoinder to express in a conversation if the related question was utilized by their partner. After being informed of the conversation topic, students were instructed to complete the questions and answers using their own information.

\subsection{Research Question}

The goal of this study was to answer the following question:

Can topic-based paired conversations utilizing a structured rotation technique improve the confidence in speaking English for EFL students?

\subsection{Description of Site and Sample}

The research was conducted at a private, girls-only junior and senior high school in central Japan. Student enrolment for the 2014-2015 school year was 1252 Japanese students. The sample used in the study was the researcher's six tenth grade English oral communication classes. In total, 237 students participated in the study. No students in the study had been diagnosed with learning disabilities, although $7 \%$ of students scored below grade-level on the Benesse standardized test of English, Japanese, and math proficiency. Of the remaining sample, $22 \%$ scored below average, $33 \%$ were average, $31 \%$ scored above average and $8 \%$ were exceptional.

\subsection{Procedures}

Mixed-methods research techniques were used in this project. The quantitative data included a pre and post intervention survey and qualitative data included teacher observations of student interactions. The surveys were used to assess the dependent variable, the students' confidence in their ability to utilize English orally. Participants completed a researcher-modified survey based on Horwitz, Horwitz, and Cope's (1986) Foreign Language Classroom Anxiety Scale (FLCAS). The FLCAS was designed to measure anxiety experienced by learners of a foreign language. The modified survey utilized a four-point Likert scale and was reduced from 33 questions to 20 questions as some of the questions were not specifically related to oral communication. Additionally, the phrase 
"foreign language" was substituted with "English conversation".

The data collection occurred during the third trimester for a period of five weeks from January 2015 to March 2015. The pre survey was completed on the day the intervention was introduced. The intervention procedure was explained and each participant received the QAC organizer. The participants were informed that the QAC was designed to facilitate the flow of the conversations by helping them review conversation patterns studied in previous lessons. Students were also provided with an example of a completed organizer covering the subject of sports. The intervention was practiced using the provided example. Upon completing the practice TT, students were introduced to the next TT subject and the researcher elicited possible questions that could be used to complete the QAC worksheet. The participants were then tasked with completing the charts individually as homework in preparation for the first TT session during the next class.

The following week, the intervention was implemented and utilized for approximately the first 25 minutes of class. During the conversations, the researcher logged observations in a journal. The researcher recorded times when pairs were resorting to Japanese language use or finished their conversations prior to the end of the allotted time. This procedure was repeated once a week for four weeks, covering four unique conversation topics. Upon completion of the final TT intervention, participants were again instructed to complete the researcher-modified survey.

\section{Results and Analysis}

\subsection{Survey Pre and Post Results}

Out of 237 survey responses, 231 were accepted for statistical analysis as six participants did not complete both surveys due to absenteeism. The four-point Likert questionnaire pre (see Table 1) and post results (see Table 2) were analysed and compared (see Table 3) using descriptive statistics. For statistical analysis purposes, responses were assigned a value of one (strongly agree) to four (strongly disagree) by the researcher. To assess the validity of the survey responses, Cronbach's Reliability Analysis was conducted with each set of surveys, indicating both the pre $(\alpha=0.7842)$ and post results $(\alpha=0.7940)$ were suitable for analysis. The mean and mode measures of central tendency were calculated for both the pre and post survey data. The analysis of the mode revealed that the most common answer for each question remained static before and after the intervention.

Table 1. Pre Survey Responses

\begin{tabular}{c|cc|cc|c|c} 
Question & \multicolumn{2}{c}{ Agree } & \multicolumn{2}{c}{ Disagree } & Mode (\#) & Mean \\
\hline 1 & 185 & $80.1 \%$ & 46 & $19.9 \%$ & Agree (120) & 1.96 \\
2 & 77 & $33.3 \%$ & 154 & $66.7 \%$ & Disagree (125) & 2.74 \\
3 & 66 & $28.6 \%$ & 165 & $71.4 \%$ & Disagree (104) & 2.93 \\
4 & 83 & $35.9 \%$ & 148 & $64.1 \%$ & Disagree (96) & 2.82 \\
5 & 123 & $53.2 \%$ & 108 & $46.8 \%$ & Agree (81) & 2.46 \\
6 & 79 & $34.2 \%$ & 152 & $65.8 \%$ & Disagree (109) & 2.80 \\
7 & 169 & $73.2 \%$ & 62 & $26.8 \%$ & Strongly Agree (89) & 2.02 \\
8 & 158 & $68.7 \%$ & 72 & $31.3 \%$ & Agree (100) & 2.13 \\
9 & 51 & $22.1 \%$ & 180 & $77.9 \%$ & Disagree (136) & 2.92 \\
10 & 71 & $30.7 \%$ & 160 & $69.3 \%$ & Disagree (100) & 2.89 \\
11 & 106 & $45.9 \%$ & 125 & $54.1 \%$ & Disagree (80) & 2.58 \\
12 & 96 & $41.6 \%$ & 135 & $58.4 \%$ & Disagree (82) & 2.71 \\
13 & 61 & $26.4 \%$ & 170 & $73.6 \%$ & Disagree (107) & 2.94 \\
14 & 25 & $10.8 \%$ & 206 & $89.2 \%$ & Disagree (105) & 3.32 \\
15 & 49 & $21.2 \%$ & 182 & $78.8 \%$ & Disagree (107) & 3.08 \\
16 & 103 & $44.6 \%$ & 128 & $55.4 \%$ & Disagree (90) & 2.57 \\
17 & 43 & $18.6 \%$ & 188 & $81.4 \%$ & Disagree (97) & 3.15 \\
18 & 142 & $61.5 \%$ & 89 & $38.5 \%$ & Agree (87) & 2.29 \\
19 & 61 & $26.4 \%$ & 170 & $73.6 \%$ & Disagree (98) & 2.97 \\
20 & 147 & $63.6 \%$ & 84 & $36.4 \%$ & Strongly Agree (80) & 2.12
\end{tabular}


Table 2. Post Survey Responses

\begin{tabular}{c|cc|cc|c|c} 
Question & \multicolumn{2}{c}{ Agree } & \multicolumn{2}{c}{ Disagree } & Mode (\#) & Mean \\
\hline 1 & 162 & $70.1 \%$ & 69 & $29.9 \%$ & Agree (116) & 2.16 \\
2 & 107 & $46.3 \%$ & 124 & $53.7 \%$ & Disagree (102) & 2.53 \\
3 & 68 & $29.6 \%$ & 162 & $70.4 \%$ & Disagree (100) & 2.93 \\
4 & 82 & $35.5 \%$ & 149 & $64.5 \%$ & Disagree (86) & 2.84 \\
5 & 121 & $52.4 \%$ & 110 & $47.6 \%$ & Agree (74) & 2.43 \\
6 & 75 & $32.5 \%$ & 156 & $67.5 \%$ & Disagree (117) & 2.77 \\
7 & 154 & $66.7 \%$ & 77 & $33.3 \%$ & Strongly Agree (87) & 2.15 \\
8 & 149 & $64.5 \%$ & 82 & $35.5 \%$ & Agree (102) & 2.23 \\
9 & 65 & $28.1 \%$ & 166 & $71.9 \%$ & Disagree (123) & 2.83 \\
10 & 87 & $37.7 \%$ & 144 & $62.3 \%$ & Disagree (98) & 2.71 \\
11 & 108 & $46.8 \%$ & 123 & $53.2 \%$ & Disagree (81) & 2.57 \\
12 & 103 & $44.6 \%$ & 128 & $55.4 \%$ & Disagree (76) & 2.65 \\
13 & 59 & $25.5 \%$ & 172 & $74.5 \%$ & Disagree (108) & 2.96 \\
14 & 29 & $12.6 \%$ & 202 & $87.4 \%$ & Disagree (115) & 3.24 \\
15 & 47 & $20.3 \%$ & 184 & $79.7 \%$ & Disagree (104) & 3.11 \\
16 & 99 & $42.9 \%$ & 132 & $57.1 \%$ & Disagree (83) & 2.67 \\
17 & 35 & $15.2 \%$ & 196 & $84.8 \%$ & Disagree (102) & 3.22 \\
18 & 136 & $58.9 \%$ & 95 & $41.1 \%$ & Agree (89) & 2.36 \\
19 & 63 & $27.3 \%$ & 168 & $72.7 \%$ & Disagree (101) & 2.94 \\
20 & 167 & $72.3 \%$ & 64 & $27.7 \%$ & Strongly Agree (87) & 2.00
\end{tabular}

Table 3. Comparison of Responses with Significant Change

\begin{tabular}{c|c|c|c|c|c|c}
\hline \multicolumn{7}{c}{ Pre Survey } \\
\hline Question & Agree & Disagree & Mean & Agree & Disagree & Mean \\
\hline 1 & 185 & 46 & 1.96 & 162 & 69 & 2.16 \\
2 & 77 & 154 & 2.74 & 107 & 124 & 2.53 \\
7 & 169 & 62 & 2.02 & 154 & 77 & 2.15 \\
9 & 51 & 180 & 2.92 & 65 & 166 & 2.83 \\
10 & 71 & 160 & 2.89 & 87 & 144 & 2.71 \\
20 & 147 & 84 & 2.12 & 167 & 64 & 2.00
\end{tabular}

\subsection{Survey Item Analysis}

Through an item analysis, it was determined that the greatest degrees of change occurred in response to the statements "I never feel quite sure of myself when I am speaking in my English conversation class," and "I don't worry about making mistakes in English conversation class." The number of students who agreed with the first statement (question one) decreased from an initial score of 80.1 percent to 70.1 percent, a difference of 10 percent (see Figure 1). The most common answer was "Agree" before and after the intervention, although the mean increased from 1.96 to 2.16. The number of students who agreed with the second statement (question two) increased from 33.3 percent to 46.3 percent after the intervention, a difference of 13 percent (see Figure 2). The most common answer was "Disagree" for both surveys but the frequency decreased from 125 to 103 . The mean also decreased from 2.74 to 2.53 . 


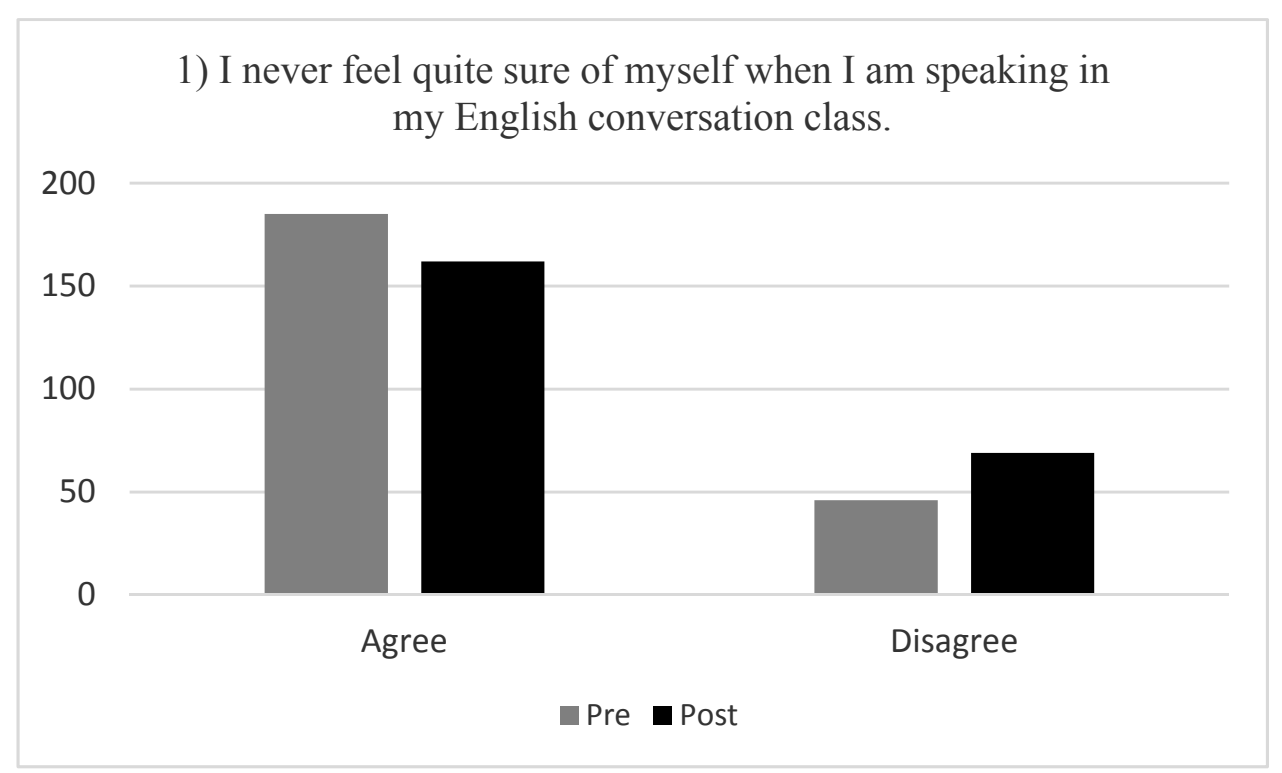

Figure 1. Comparison of Question 1 Pre and Post Results ( $\mathrm{n}=231)$

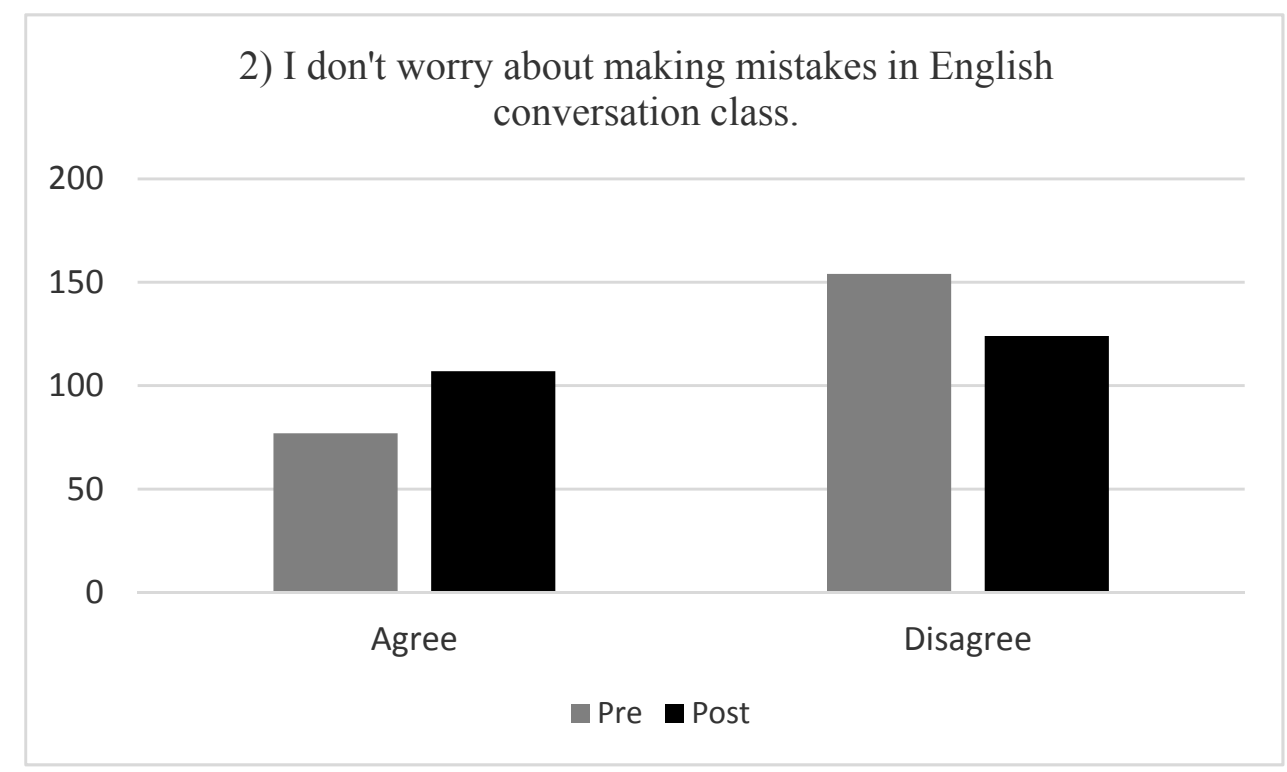

Figure 2. Comparison of Question 2 Pre and Post Results $(\mathrm{n}=231)$

Moderate changes were measured in questions seven (6.5\%), nine (6\%), ten (7\%), and twenty (8.7\%). In response to question seven, "I keep thinking that other students are better at English conversation than I am," 6.5 percent more students disagreed with the statement after the intervention. The most common answer was "Strongly Agree" both before and after the intervention. Analysis of responses to question nine, "I don't understand why some people get so upset over English conversation class," revealed that 6 percent more students agreed with the statement after the intervention. Regarding the statement from question ten, "In English conversation class, I can get so nervous I forget things I know," 7 percent more students endorsed the statement on the post survey. The mode was "Disagree" for both surveys. The number of responses decreased from 89 to 87 while the mean value decreased from 2.89 to 2.71 . The responses to question twenty, "I feel overwhelmed by the number of rules you have to learn to speak English," revealed that 8.7 percent more students agreed with the statement by the conclusion of the project. The most 
common answer was "Strongly Agree" in both the pre and post surveys and the number increased from 80 to 87 , while the mean value decreased from 2.12 to 2.0.

Questions eight (4.2\%), twelve (3\%), seventeen (3.4\%) and eighteen (2.6\%) revealed minor degrees of change. The questions with the smallest degrees of change were questions three through six, eleven, thirteen through sixteen, and nineteen, each of which revealed a difference of less than 2 percent after the intervention.

\subsection{Observational Data}

Observational data was collected throughout the intervention. Observations were grouped into two general categories: instances of native language (L1) use (see Table 4) and pairs of students unable to converse (see Table 5). Examples of L1 use were defined as students being unable to respond to a question in English and utilizing the native language in order to communicate. Minor utterances to pause for time, or think while generating a response, were not counted. A pair of students unable to converse was defined as a time when both members reverted to speaking completely in Japanese before the end of the round, or were reticent.

Table 4. Instances of L1 Use

\begin{tabular}{lllllllll}
\hline Week & Class A & Class B & Class C & Class D & Class E & Class F & Total & Mean \\
\hline 1 & 12 & 12 & 14 & 17 & 8 & 13 & 76 & 12.7 \\
2 & 13 & 17 & 15 & 14 & 14 & 12 & 85 & 14.2 \\
3 & 11 & 13 & 8 & 9 & 12 & 8 & 61 & 10 \\
4 & 6 & 10 & 13 & 10 & 11 & 3 & 53 & 8.8
\end{tabular}

Table 5. Pairs of Students Unable to Converse

\begin{tabular}{lllllllll}
\hline Week & Class A & Class B & Class C & Class D & Class E & Class F & Total & Mean \\
\hline 1 & 7 & 6 & 6 & 4 & 1 & 4 & 28 & 4.7 \\
2 & 0 & 4 & 6 & 10 & 10 & 5 & 35 & 5.8 \\
3 & 1 & 3 & 4 & 2 & 3 & 1 & 14 & 2.3 \\
4 & 1 & 2 & 2 & 3 & 1 & 3 & 12 & 2
\end{tabular}

The frequency of L1 use decreased from an average of 14.2 times per class in week two, to an average of 8.8 times per class during the final week of the intervention. The students unable to converse decreased from an average of 5.8 instances per class in week two, to an average of two instances per class in the final week of the intervention.

\section{Discussion}

\subsection{Strengths and Limitations}

There were several strengths to the intervention. The question-answer-comment (QAC) organizer was vital to the success of the intervention. Due to the diverse ability levels within each class, a tool was necessary to facilitate a back-and-forth dialogue between the students. Although not all students put in adequate effort in completing the organizers that were assigned as homework, those who did were clearly observed being able to converse for longer periods of time. Students who did not complete the QAC often remained in silence, resorted to L1 use, or utilized their partner's organizer in an attempt to create a dialogue.

An additional strength of the activity was that it helped create a supportive atmosphere for the students. Once students understood the expectations and of the intervention, they began to work with each other to complete their work. Students with higher ability were generally patient and encouraged their partners with lower ability. Additionally, some students were observed asking other groups what the English equivalent of a Japanese word was, and then utilized the new word with their partner to continue the conversation. 
There were also several limitations of this action research. The first was the sample. Although the final number of participants was 231, they were all adolescent females between the ages of 15 and 16 . A study with participants from both genders would have added a variable that could have potentially produced drastically different results.

The second limitation to this study was the lack of opportunities to conduct the intervention. The research occurred during the third and shortest trimester of the school year spanning from January until March. During this period, there were only six class periods during which the intervention could be utilized. In addition to the lack of class time, due to various school events and schedule changes, some classes did not meet in consecutive weeks. Although the English communication course is compulsory, it is not considered a core subject, and students often neglected or simply forgot to complete their homework. A greater degree of change could have been measured had the students had consistent opportunities to participate in the activity.

A final limitation to the study was the degree to which the students understood what they were saying or whether they were using English correctly in the proper context. Although the goal of the study was to improve student confidence to utilize English orally, the ultimate purpose of speaking any language is communication. The organizer was intended to serve as a brainstorming tool to facilitate communication, but it was observed that a number of students simply copied a classmate's work prior to the class. This cast doubt as to whether students comprehended what they were saying. The organizers were also not corrected until after the speaking activity, so some students practiced English using unnatural phrases or incorrect grammar.

\subsection{Implications}

Consistency and structured activities are a vital aspect of instruction when teaching English to foreign learners. Week after week as the intervention was conducted, students were observed putting more effort into completing their homework and appeared less reticent when being asked to speak to their partners in English. The step-by-step and timed nature of the intervention clearly was effective in engaging the students. They understood the expectations and felt motivated to speak until the teacher instructed them to stop conversing. Additionally, the student-centered activity allowed students with higher ability to take initiative and mentor their classmates, providing another avenue for student growth. Through this research, I came to understand that motivating students to speak English is not an unattainable when students are provided with a proper foundation to communicate.

\section{Conclusion}

\subsection{Connection to Related Studies}

The results of this research supported the findings of previous studies. Harumi (2011) suggested that to reduce reticence, activities should be structured in a step-by-step approach to build confidence and facilitate learner autonomy in a classroom that encouraged mutual participation. The structured natured of the intervention provided a foundation that showed positive gains over the course of the study, not only in the students' communicative abilities and habits, but their investment in their homework and focus during class.

Osterman (2014) concluded that a more communicative and less grammar-focused classroom would be more conducive to the facilitation of willingness to communicate (WTC) and English language learning. The activity discussions were unstructured, casual conversations. Students were encouraged to discuss the topics freely and did so using their homework as a tool to facilitate communication. The homework was only corrected after completing activity. Although this process resulted in some students practicing improper English phrases, they conversed actively in a positive manner.

Finally, Talandis Jr. and Stout (2014) determined that frequent assessments helped motivate reluctant learners to practice with greater focus and intensity. Although there were some exceptions, the quality of homework progressively increased as a result of the intervention. The structure and clear expectations had an impact on students' motivation in the class. In addition, gaps in student vocabulary and grammatical knowledge came to light, as common mistakes were observed reoccurring from week to week.

\subsection{Recommendations for Future Research}

Due to the positive results of the study, I believe further research is necessary in the field of facilitating oral communication in the EFL classroom. As one of the limitations of this study was its duration, I believe a longitudinal study would be much more effective in truly having a long-lasting impact on improving students' confidence to speak. The gains from this study made in the short term have demonstrated promise, but I believe many students may revert to older tendencies once they return to a more traditional curriculum of study. 
I intend to use this exercise in the future with modifications. Instead of changing topics each week it would be beneficial to have students complete the conversation topics over multiple weeks, similar to a process conducted in a study by Talandis Jr. and Stout (2014). Because students often completed the conversations using homework that contained mistakes, it would be beneficial for students to have a second opportunity to converse using the corrected English. Another chance to meet utilizing the same topic would also provide an opportunity to address common mistakes and respond to student inquiries. Finally, reducing the number of pair conversations from three to two may also produce more promising results. Although students were generally able to speak for the third and final pairing, some students were observed losing interest in the discussion after having already completed it twice.

\section{Acknowledgements}

I appreciate the contributions made by my colleague Alexandra Gellin in helping me to complete this research. Her opinions, advice, and assistance throughout the project provided invaluable insight into the process of research. I am also grateful to Chiho Tajima for assisting me in translating my assessment tool into the Japanese language.

\section{References}

Harumi, S. (2011). Classroom silence: Voices from Japanese EFL learners. ELT Journal, 65(3), 260-269. http://dx.doi.org/10.1093/elt/ccq046

Horwitz, E.K., Horwitz, M. B., \& Cope, J. (1986). Foreign language classroom anxiety. The Modern Language Journal, 70(2), 125-132. http://dx.doi.org/10.1111/j.1540-4781.1986.tb05256.x

Osterman, G. (2014). Experiences of Japanese university students' willingness to speak English in class: A multiple case study. SAGE Open, July-September 2014, 1-13. http://dx.doi.org/10.1177/2158244014543779

Saito, H., \& Ebsworth, M. (2004). Seeing English language teaching and learning through the eyes of Japanese EFL and ESL students. Foreign Language Annals, 37(1), 111-124.

Sakui, K. (2007). Classroom management in Japanese EFL classrooms. The Japan Association for Language Teachers Journal, 29(1), 41-58.

Talandis Jr., G., \& Stout, M. (2014). Getting EFL students to speak: An action research approach. ELT Journal, 69(1), 11-25. http://dx.doi.org/ 10.1093/elt/ccu037

Watanabe, M. (2013). Willingness to communicate and Japanese high school language learners. The Japan Association for Language Teachers Journal, 35(2), 153-172. 